\title{
Interações Iniciais Mãe-bebê
}

\author{
Maria Lucia Seidl de Moura ${ }^{12}$ \\ Adriana Ferreira Paes Ribas \\ Universidade do Estado do Rio de Janeiro \\ Karla da Costa Seabra \\ Universidade do Estado do Rio de Janeiro \\ Universidade Estácio de Sá \\ Luciana Fontes Pessôa \\ Rodolfo de Castro Ribas Jr. \\ Susana Engelhard Nogueira \\ Universidade do Estado do Rio de Janeiro
}

\begin{abstract}
Resumo
Este estudo visou a analisar características das interações iniciais mãe-bebê em um contexto urbano brasileiro; as relações entre características de interações, atividades maternas e a concepção acerca das competências dos bebês; e as relações entre características destas atividades e o estado de vigília dos bebês. A amostra foi constituída por 30 díades. Os bebês tinham idade média de 29 dias. Registrou-se em vídeo as atividades da díade durante 20 minutos. Foi aplicado um questionário às mães. Os dados foram analisados em termos da percentagem de ocorrências das atividades da díade e de interação. Os episódios de interação identificados foram de curta duração, predominantemente face-a-face, têm contextos específicos de troca e se caracterizam principalmente por atividades sociais. Os bebês foram avaliados como ativos, participantes das trocas sociais. Os resultados contribuem com elementos importantes para discussão da natureza dos primeiros processos interacionais.

Palavras-chave: Interação mãe-bebê; interação precoce; desenvolvimento inicial.
\end{abstract}

Initial Mother-infant Interactions

\begin{abstract}
This study aimed at analyzing the characteristics of initial mother-baby interactions in a Brazilian urban environment; the relationship between the interaction characteristics, mother's activities and their conception about the baby's competences; and the relationship between the characteristic of those activities and the baby's awareness state. A sample of 30 motherbaby dyads was observed. The dyads consisted of mothers and her babies who were, on average, 29-days old. The dyads were videotaped for 20 minutes and the mothers were asked to answer a questionnaire. The data were analyzed in terms of the percentage of the occurrences of the dyad's activities and interaction. The episodes of interaction observed were short-term, mainly face-to-face, having a specific context and mostly distinguished as social activities. The babies were evaluated as active and participant in the social exchange. The results contribute with important elements for the discussion of the nature of the first interactional processes.

Keywords: Mother-infant interaction; early interaction, initial development.
\end{abstract}

Investigações sobre interação mãe-bebê em etapas iniciais do desenvolvimento mostram-se relevantes por diversas razões. Pressupondo-se que interações sociais são fatores que engendram o desenvolvimento humano (Vygotsky, 1984), pode-se argumentar, em primeiro lugar, que conhecer características das interações mãe-bebê, em fases iniciais do desenvolvimento contribui significativamente para um

\footnotetext{
${ }^{1}$ Os autores agradecem aos demais membros do grupo de pesquisa: Flávia Gomes Luz, Guilherme de Carvalho, Ivoneide Viana da Silva e Michele Siviero Martins. Desejam também expressar sua gratidão às mães que aceitaram participar do estudo e às entidades financiadoras: UERJ, FAPERJ E CNPQ

${ }^{2}$ Endereço para correspondência: Rua Fritz Feigl, 465, Eldorado, Freguesia, Jacarepaguá, 22750 600. Fone: (21)24471588, Fax: (21)25877284. E-mail: mlseidl@alternex.com.br
}

melhor entendimento do processo de desenvolvimento humano. Em segundo lugar, pode-se também afirmar que a carência de estudos brasileiros sobre interações nesse período do desenvolvimento deixa uma lacuna que precisa ser preenchida. Os bebês recém-nascidos apresentam um conjunto de características que os capacitam para os primeiros contatos sociais. Entretanto, a existência de trocas mãe-bebê no primeiro mês de vida do bebê que possam ser consideradas interações sociais, bem como características dessas interações, são problemas que devem ser investigados em diferentes culturas (Tomasello, 1999).

O presente trabalho dá continuidade a estudos anteriores (Ribas \& Seidl de Moura, 1998; Seidl de Moura \& Ribas, 1996) e tem quatro objetivos: 1) investigar características das 
interações iniciais mãe-bebê em um contexto urbano brasileiro; 2) investigar as relações entre essas características e a concepção das mães acerca das competências dos bebês; 3) avaliar relações entre a ocorrência de determinadas atividades das mães (Ex.: fala e atribuição de significado e/ou intenção aos comportamentos do bebê) e a concepção materna acerca das competências dos bebês; 4) estudar as relações entre atividades das mães e o estado de vigilia dos bebês.

Conforme destacam Smotherman e Robinson (1996), no período logo após o nascimento pode-se claramente observar interações entre bebês e seus cuidadores. Para Vinter (1987) há uma espécie de pré-adaptação que propicia, desde o nascimento, a construção de um sistema de comunicação mãe-bebê. No curso das primeiras semanas, os bebês apresentam uma ligação estreita entre os sistemas de percepção e ação organizada, parecendo predispostos a responder seletivamente a estímulos sociais (Rochat, 2001). Segundo Trevarthen e Hubley (1978), os recém-nascidos possuem uma motivação básica para se relacionar com pessoas. Durante este período os bebês estão sintonizados socialmente e sua perspectiva em relação às pessoas é 'atencional', ainda sem sinais de intersubjetividade (Rochat \& Striano, 1999). Os bebês apresentam, no entanto, uma vida subjetiva, traços de temperamento duradouros e linhas de base afetivas particulares que fazem parte de seu senso privado de self (Rochat, 2001). Nas interações mãe-bebê, os afetos, sentimentos e emoções de um ecoam os do outro por espelhamento, contágio ou reações contingentes dentro de um curto espaço de tempo. É isto que permite o desenvolvimento da intersubjetividade.

No segundo mês, bebês apresentam os primeiros sinais de "intersubjetividade primária" (Rochat \& Striano, 1999). Esta é uma forma de interação que se apresenta nos primeiros meses de vida do bebê (entre os 2 e 3 meses) e tem como aspectos essenciais o interesse que o bebê demonstra pela fala da mãe e sua capacidade, nas primeiras trocas entre os dois, de orientar sua atenção para o rosto da mãe e de responder imediatamente às solicitações dela. Respondendo a estas características dos bebês, e orientados pelos sistemas de cuidados parentais (Keller, 1998) os adultos que deles cuidam são muito sensíveis às pistas que eles emitem.

O reconhecimento da competência do recém-nascido, quanto à sua capacidade de percepção, imitação e comunicação, ou seja, de sua pré-adaptação para iniciar o conhecimento do meio no qual está inserido, em termos físicos e sociais, evidencia o papel ativo do bebê no mundo e nas relações diádicas. Segundo Brazelton e Cramer (1992), as mães apresentam, em graus variados, a capacidade de reconhecer as necessidades, preferências, limites do bebê. Elas reconhecem ainda a forma peculiar de comunicação dos bebês, ajustando seu comportamento a esses aspectos. Ajustes são também realizados pelo bebê (Heckhausen, 1987). Tanto a criança age sobre sua mãe através de olhares e mímicas, quanto a mãe age sobre ele por meio de sua fala e movimentação (Robin,
1980). No caso da mãe há um ajuste intuitivo e preciso de sua atividade às capacidades do bebê (Bruner, 1983), um ajuste que pode ser percebido, inclusive, em termos de linguagem (Ex.: Snow, 1994).

Para caracterizar as interações mãe-bebê, dois elementos parecem fundamentais: a reciprocidade e a comunicação (Ribas, 1996). Argumenta-se que a interação exige que os parceiros respondam aos comportamentos um do outro e que seja, sobretudo, sustentada por ambos. Essa reciprocidade parece ser encontrada desde fases iniciais do desenvolvimento do bebê e pode ser inferida, por exemplo, no processo de afiliação descrito por Bruner(1983) enas evidências produzidas pelos experimentos de rosto imóvel (Ex.: Brazelton \& Cramer, 1992). Além da reciprocidade, é preciso considerar, segundo Ribas (1996), que ocorre algum nível de comunicação entre a mãe e o bebê. Essa comunicação pode se dar de diferentes formas: através do contato olho a olho, sorrisos, vocalizações, posturas, gestos, expressões faciais, tom de voz, aproximação e afastamento corporal, brincadeiras e do choro. Mãe e bebê são sensíveis aos sinais um do outro e respondem a eles. No caso da mãe, pode-se inclusive verificar a atribuição de significados de acordo com os contextos de troca e de seu conhecimento do bebê. Esse processo de atribuição de significado é mediado pelas representações da mãe acerca do mundo, de um modelo geral de infância e, ainda, de um conjunto de representações e expectativas do bebê e de seu desenvolvimento. É no processo de interação e na negociação de significações nele envolvida que se desenvolvem esses meios de comunicação, de "fazer sentido um para o outro". O sistema de comunicação que se estabelece entre a mãe e o bebê, e que possibilita trocas interacionais entre eles, sofre transformações intimamente ligadas ao próprio desenvolvimento do bebê.

Características das interações iniciais mãe-bebê têm sido estudadas (Ex.: Brazelton \& Cramer, 1992; Osofsky \& Connors, 1979), inclusive longitudinal e transculturalmente (Ex.: Bornstein, Maital, Tal \& Baras, 1995; Bornstein \& Tamis-LeMonda, 1990), sendo observadas transformações nessas trocas. Para Bornstein e colaboradores, o engajamento entre os parceiros é inicialmente interpessoal e voltado para a própria díade, caracterizando o que denominam como 'domínio social'. Gradativamente, entretanto, estas interações se transformam com a inclusão de elementos do contexto trazidos pela mãe, a partir de pistas do bebê ou de seu próprio interesse, configurando um 'domínio didático' (Bornstein \& cols., 1995). Os estudos realizados, no entanto, têm utilizado, basicamente, amostras com bebês de 02 meses de idade, sendo relativamente raro acompanhar bebês menores.

As transformações descritas por Bornstein e colaboradores (1995) foram corroboradas em uma pesquisa longitudinal de uma díade mãe-bebê ao longo de 5 meses (Ribas, 1996). Quatro momentos do desenvolvimento do bebê: 02; 10; 15 e 21 semanas foram analisados, observando-se aumento na freqüência de ocorrências de interações, assim como uma 
modificação na natureza das mesmas. Quando o bebê tinha 2 semanas, o olhar e o contato físico foram os elementos essenciais para o estabelecimento e manutenção das interações, caracterizadas como exclusivamente de domínio social. Nas observações posteriores, as modalidades de comunicação foram se ampliando. Mostrar e olhar para objetos são incluídos, por exemplo. A díade começa a incorporar elementos do mundo exterior às interações.

Algumas atividades das mães parecem ser especialmente importantes no primeiro ano de vida do bebê, pelo menos em algumas culturas ocidentais. O predomínio da atividade da mãe de olhar o bebê também foi identificado por Kaye e Fogel (1980), em uma pesquisa longitudinal na qual foi verificado que mães de bebês de 6; 13 e 26 semanas despendiam cerca de $100 \%$ do tempo de observação olhando os bebês diretamente. $\mathrm{O}$ toque pelas mães também foi apontado por estes autores como de fundamental importância no sentido de atrair a atenção dos seus bebês. Ao mesmo tempo, observou-se um declínio significativo da proporção de tempo durante o qual as crianças mantêm a atenção nas faces das mães. Os bebês, que inicialmente estão mais voltados para o estímulo potente que é a face humana, aos poucos incluem nas suas preferências visuais, além do rosto humano, objetos animados e inanimados do ambiente.

Além dessas transformações relacionadas ao curso da ontogênese do bebê, as formas que as trocas interacionais mãe-bebê assumem podem variar, de acordo com a diversidade de contextos socioculturais nos quais estão inseridas. Se as características dos bebês recém-nascidos são consideradas universais, assim como as propensões parentais e a presença de trocas interacionais, a forma que assumem e suas características são relativas ao contexto sociocultural. LeVine (1989) discute esta questão apontando que as condições em que se dá o desenvolvimento inicial em sociedades não ocidentais são bastante diversas das do ocidente. Neste sentido, os padrões de interação devem ser investigados considerando a variação cultural nos ambientes iniciais de desenvolvimento. Aqui, uma referência às idéias de Keller (1998) é especialmente útil. Para ela, pelo menos duas trajetórias ontogenéticas típicas podem ser identificadas, uma ocidental e outra não ocidental (e não urbana, principalmente), sendo cada trajetória associada a um modo de investimento parental. No modo não ocidental, o cuidado físico inclui a amamentação durante 2 a 4 anos, o bebê é carregado durante seus primeiros anos mais do que $50 \%$ do tempo, o contato corporal se dá durante o dia e a noite (nas costas, na frente ou no quadril da mãe), as crianças dormem com os adultos e os cuidados extras são oferecidos à criança por outros parentes e irmãos. Em contraste, no modo ocidental, o cuidado físico é caracterizado por um período de amamentação em média bem mais curto (de 1 a 3 meses), por reduzidos períodos de carregar o bebê, principalmente em resposta a seu choro, e por pouco contato corporal, ficando o bebê principalmente no berço e em carrinhos. Os cuidados extras oferecidos são, em geral, pagos (Ex.: babás, creches).

Keller (1998) classifica os ambientes sociais do desenvolvimento humano como 'diádicos' (os bebês são cuidados, basicamente, por um adulto, freqüentemente a mãe ou um(a) substituto(a), de maneira exclusiva) ou como 'múltiplos' (os cuidados com o bebê são divididos entre os membros do grupo social) e aponta ainda diferenças no modo como é dada atenção ao bebê. Esta atenção poderia ser co-ativa (a mãe realiza atividades cotidianas carregando seu bebê) ou exclusiva (outras atividades não são realizadas simultaneamente aos cuidados do bebê). Os modos de cuidado ocidental e não ocidental se diferenciam tanto em relação ao ambiente social, quanto a tipo de atenção despendida com o bebê. O modo não ocidental teria ambiente social múltiplo e estrutura atencional co-ativa, enquanto que o modo ocidental apresentaria um ambiente social diádico e a estrutura atencional exclusiva. Ainda segundo Keller (1998), nos ambientes diádicos exclusivos (crib and cradle cultures) parece predominar um modo de interação que focaliza ou que se baseia principalmente em comunicação visual e trocas vocais/verbais. Nos ambientes múltiplos e co-ativos, os bebês são carregados quase o tempo todo. Desta forma, o contato corporal é bem maior e as pistas que a mãe e o bebê recebem um do outro são táteis e auditivas.

Mesmo em cada um desses dois modos de investimento parental, podem ser observadas diferenças relativas a padrões culturais específicos. Bornstein e colaboradores (1995), por exemplo, identificaram que mães israelenses tendem a interagir com seus bebês de 5 meses de uma forma mais autônoma do que as mães americanas. Da mesma forma, Fogel, Toda e Kawai (1988) encontraram diferenças interessantes em seu estudo que compara o microcontexto de interações lúdicas em díades mãe-bebê com 3 meses, no Japão e nos Estados Unidos. Os resultados indicaram que as mães das duas culturas responderam contingentemente aos comportamentos dos bebês, mas apresentaram diferenças tanto no tipo de resposta, como em seu ritmo. As mães japonesas usaram mais contingentemente e, simultaneamente, uma variedade maior de estimulação visual não verbal, e usaram o toque com maior freqüência. Em contraste, essas mães não responderam simultaneamente às vocalizações dos bebês ou usaram suas próprias vocalizações como respostas. Por outro lado, as mães americanas aproximaram mais suas faces das dos seus bebês e ofereceram a eles principalmente estimulações faciais e vocais.

Apesar dessas investigações e do rico corpo de evidências que proporcionam, considera-se que são ainda necessárias pesquisas em diferentes culturas para avaliar as diferenças nos dois componentes de comportamento parental e na 
distribuição dos vários sistemas parentais para se compreender as características comuns e as variações culturais nas interações iniciais. Constatando-se a carência de estudos brasileiros sobre o tema, este trabalho visa preencher parcialmente essa lacuna e oferecer algumas evidências sobre interações iniciais em díades mãe-bebê em contexto urbano.

\section{Método}

\section{Amostra}

Participaram 30 díades mãe-bebê. As mães tinham entre 17 e 39 anos ( $m=28$ anos) e apresentavam níveis de instrução variados: fundamental ( $n=6)$, médio $(n=7)$ e superior $(n=17)$. Os bebês tinham entre 22 e 37 dias ( $m=29$ dias) na ocasião da observação. O grupo tinha aproximadamente o mesmo número de mães que trabalhavam fora $(n=16)$ e que não trabalhavam $(n=14)$. Na ocasião da observação, as mães que trabalhavam fora de casa estavam de licença maternidade.

As famílias residiam em bairros distribuídos por diversas regiões das cidades de Nova Iguaçu, São Gonçalo e Rio de Janeiro. Quase todas as díades pertenciam a familias nucleares, constituídas por pai, mãe e um ou mais filhos.

\section{Instrumento}

Foi utilizado o Questionário sobre a Concepscão de Competências do Bebê Recém-Nascido (QCBR, IF Guttman split-balf=0,86), que inclui 35 itens distribuídos nas seguintes áreas, identificadas através da análise de componentes principais (Ribas \& Seidl de Moura, 1995): área I - Capacidades sensoriais e de imitação que possibilitam ao bebê um conhecimento do mundo e das pessoas; área II - Diferenças individuais entre bebês e sua capacidade de interagir com o mundo e pessoas; área III - Possibilidade de participação ou alheamento nas interações.

\section{Procedimentos}

Antes de aceitarem participar da pesquisa, as mães receberam esclarecimentos necessários sobre sua natureza, sobre o sigilo e confidencialidade das respostas, sobre o uso restrito das imagens em vídeo e sobre o caráter voluntário da participação. As díades mãe-bebê foram visitadas em suas residências, em uma situação em que apenas a mãe e o bebê estavam presentes. A mãe foi solicitada a manter a sua rotina diária e a ignorar a presença do observador, na medida do possível. Foi realizado o registro em vídeo da díade, iniciado após 10 minutos de familiarização com o observador e durante 20 minutos. Depois disso, foi aplicado o questionário (QCBR) à mãe.

Dos 20 minutos de vídeo, foram desconsiderados 5 minutos (iniciais ou finais), sendo analisados os 15 minutos restantes, em intervalos fixos de 30 segundos. Os dados foram inicialmente levantados registrando-se as ocorrências de atividades da mãe e do bebê nos intervalos. Foram identificadas seqüências de atividade conjunta, consideradas como instâncias de interação.
Foram descritos, ainda, os contextos específicos de troca (Ex.: amamentação, mãe cuidando do bebê) em cada um dos intervalos e identificados os estados de vigilia dos bebês. Além disso, foram transcritas todas as falas e vocalizações da mãe durante a observação.

Inicialmente os dados foram analisados em termos da percentagem de ocorrências das atividades da mãe e do bebê e das ocorrências de interação, de domínio social e mediado por objetos. Em seguida, foi elaborado um quadro comparativo das atividades realizadas pela mãe e pelo bebê nos 30 intervalos, seguido de uma análise qualitativa destas atividades. Os episódios de interação identificados foram analisados em termos da sua descrição, contexto específico de troca, quadro descritivo e duração. Foi ainda realizada uma análise qualitativa das interações, considerando aspectos como: natureza das atividades dos parceiros, ocorrência ou não de ajustes, por parte da mãe, no sentido de favorecer interações, cenários mais freqüentes de ocorrência de interação, entre outros. Foram também descritas as tentativas de interação não efetivadas.

As falas e vocalizações da mãe durante a observação foram analisadas quantitativamente, em termos da ocorrência de atribuição de significado e intenção aos comportamentos do bebê, e qualitativamente, em termos da natureza dessa atribuição. Em relação ao QCBR, foram computados os escores totais e parciais obtidos pelas mães.

\section{Codificação de Dados}

Os registros em vídeo foram analisados com o objetivo de identificar: interações mãe-bebê, atividades da mãe e do bebê, estados de vigilia do bebê e contextos específicos de troca. As atividades da mãe e do bebê foram observadas na tentativa de caracterizar instâncias de interação e não como alvo principal. As interações foram ainda categorizadas em dois domínios mutuamente excludentes e exaustivos: domínio social de interação (DS) e domínio de interação mediado por objetos (DMO). As tentativas de interação não efetivada $(\mathrm{T})$ também foram identificadas e analisadas.

As atividades da mãe consideradas foram: gestos $(G)$, vocalizações $(\mathrm{V})$, fala $(\mathrm{F})$, atribuição de significado (AS), sorrir (S), toque (T), olhar o bebê (OB), mostrar objeto (MO), cantar (CA) e pegar no colo (PC). A atribuição de significado foi adicionalmente classificada em: preferências/ vontade, estados emocionais, condição/sensação física, necessidades básicas/ fisiológicas e capacidade cognitiva.

Foi adotada a categorização utilizada por Rosenthal (1983) em relação aos estados de vigilia dos bebês: dormindo (estado 1), sonolento (estado 2), acordado (estado 3), inquieto (estado 4) e chorando (estado 5). Os contextos específicos de troca foram definidos como os cenários mais comuns de trocas entre as díades, incluindo, por exemplo, o de amamentação, de cuidados do bebê, e o de ficar com o bebê no colo. 


\section{Resultados e Discussão}

Considerando a percentagem de ocorrências nos intervalos, verificou-se que as atividades predominantes das mães nos períodos observados foram: olhar o bebê $(99,2 \%)$ e tocar o bebê $(83,4 \%)$, confirmando algumas evidências da literatura, como dos estudos de Kaye e Fogel (1980) e Ribas (1996), já citados. Estes achados sugerem a importância das atividades de olhar e tocar no processo interacional mãe-bebê. Os dados relativos à percentagem de ocorrência de atividades das mães e bebês e ocorrências de interação são apresentados na Tabela 1 .

Apesar de ser necessário considerar a existência de uma ampla gama de diferenças individuais entre os bebês já no nascimento, parece razoável considerar a existência também de um repertório comum de atividades características de bebês nesta fase. Nesta investigação, considerando a percentagem de ocorrências nos intervalos, foi verificada a predominância das seguintes atividades dos bebês: olhar o ambiente (54\%), vocalizar (48,9\%), olhar a mãe $(39,6 \%)$ e mamar (38,1\%).
Essas atividades ocorreram em variados estados de vigilia do bebê. Foram calculadas as percentagens de ocorrência dos diferentes estados, indicando uma variação entre os estados $1 \mathrm{e}$ 5. Pelo procedimento adotado, a díade não era observada se o bebê adormecesse. Consistentemente com os critérios adotados, o estado mais freqüente no qual os bebês foram observados foi o estado acordado.

Foram identificados episódios de interação em 22 das 30 díades observadas. Os episódios de interação ocorreram, em média, em torno de $9 \%$ dos intervalos. Todos foram de domínio social, confirmando evidências da literatura. As mães, inicialmente, mostram-se mais voltadas para conhecer o bebê do que para apresentar a ele objetos e eventos, iniciativas que aumentam progressivamente.

A natureza das interações em um período tão precoce do desenvolvimento apresenta peculiaridades, como as limitações do repertório de comportamentos do bebê, da própria mãe, na medida em que ela seleciona os meios pelos quais interage com o bebê de acordo com o repertório do bebê, e também dos contextos específicos de troca.

Tabela 1

Ocorrência de Interação e Atividade nos Diferentes Estados de Vigília

Distribuição de Atividades (n) Considerando Estados N=900 intervalos

\begin{tabular}{|c|c|c|c|c|c|c|c|c|c|c|c|c|c|c|c|}
\hline$\overline{\text { Estado }}$ & $\overline{D S O C}$ & DDID & $\overline{\text { Tenta }}$ & Mgesto & $\overline{\text { Mvocali }}$ & Mfala & MSorri & i & $\overline{\text { MToque } \mathrm{N}}$ & Molha & Mmostra & $\overline{\text { MCanta } 1}$ & $\overline{\text { MColo N }}$ & $\overline{\mathrm{MASig} B \mathrm{BC}}$ & IhaA \\
\hline$\overline{1}$ & 0 & 0 & 0 & 0 & 4 & & 9 & 2 & 19 & 19 & 0 & 1 & 0 & 2 & 4 \\
\hline 2 & 18 & 0 & 7 & 1 & 30 & & 136 & 18 & 183 & 252 & 3 & 8 & 3 & 49 & 62 \\
\hline 3 & 77 & 0 & 14 & 3 & 80 & & 105 & 61 & 500 & 583 & 6 & 13 & 39 & 122 & 390 \\
\hline 4 & 6 & 0 & 1 & 1 & 38 & & 130 & 10 & 148 & 160 & 1 & 2 & 16 & 44 & 115 \\
\hline 5 & 1 & 0 & 0 & 0 & 24 & & 88 & 8 & 97 & 101 & 0 & 0 & 17 & 17 & 59 \\
\hline Total Absoluto & 81 & 0 & 21 & 3 & 124 & & 75 & 76 & 751 & 893 & 8 & 16 & 48 & 175 & 487 \\
\hline
\end{tabular}

Distribuição de Atividades (\%) Considerando Estados/Percentagem geral

\begin{tabular}{lrlrrrrrrrrrrrr}
\hline & Estado & DSOC & DDID & Tenta & \multicolumn{1}{c}{ Mgesto Mvocali Mfala } & \multicolumn{1}{c}{ MSorri } & \multicolumn{3}{c}{ MToque } & Molha & Mmostra & MCanta MColo MASig BOllhaA \\
1 & 0,00 & 0,00 & 0,00 & 0,00 & 0,44 & 1,00 & 0,22 & 2,11 & 2,11 & 0,00 & 0,11 & 0,00 & 0,22 & 0,44 \\
2 & 2,00 & 0,00 & 0,78 & 0,11 & 3,33 & 15,11 & 2,00 & 20,33 & 28,00 & 0,33 & 0,89 & 0,33 & 5,44 & 6,89 \\
3 & 8,56 & 0,00 & 1,56 & 0,33 & 8,89 & 45,00 & 6,78 & 55,56 & 64,78 & 0,67 & 1,44 & 4,33 & 13,56 & 43,33 \\
4 & 0,67 & 0,00 & 0,11 & 0,11 & 4,22 & 14,44 & 1,11 & 16,44 & 17,78 & 0,11 & 0,22 & 1,78 & 4,89 & 12,78 \\
5 & 0,11 & 0,00 & 0,00 & 0,00 & 2,67 & 9,78 & 0,89 & 10,78 & 11,22 & 0,00 & 0,00 & 1,89 & 1,89 & 6,56 \\
Total Absoluto & 9,00 & 0,00 & 2,33 & 0,33 & 13,78 & 63,89 & 8,44 & 83,44 & 99,22 & 0,89 & 1,78 & 5,33 & 19,44 & 54,11 \\
\hline
\end{tabular}

Distribuição de Atividades (n) Considerando Estados $\mathrm{N}=900$ intervalos

\begin{tabular}{|c|c|c|c|c|c|c|c|c|c|c|c|c|c|c|}
\hline Estado & BMMem & TocaM & Bmama & BPegaO & BVocaliza & BSorri & $\mathrm{BFOll}$ & $\mathrm{BCl}$ & $\mathrm{B} 2 \mathrm{~V}$ & EB2V1 & EB2V2 & EB2V3 & EB2V4 & $\overline{\mathrm{B} 2 \mathrm{~V} 5}$ \\
\hline 1 & 16 & 2 & 3 & 0 & 8 & 0 & 13 & 0 & 0 & 19 & 8 & 1 & 2 & 1 \\
\hline 2 & 167 & 59 & 177 & 0 & 70 & 0 & 120 & 6 & . & 8 & 256 & 81 & 12 & 3 \\
\hline 3 & 521 & 218 & 178 & 0 & 303 & 2 & 46 & 25 & 0 & 1 & 81 & 588 & 89 & 47 \\
\hline 4 & 159 & 91 & 32 & 0 & 157 & 1 & 14 & 40 & 0 & 2 & 12 & 89 & 160 & 47 \\
\hline 5 & 102 & 51 & 9 & 0 & 98 & 0 & 11 & 30 & 0 & 1 & 3 & 47 & 47 & 102 \\
\hline oluto & 753 & 297 & 343 & 0 & 440 & 2 & 170 & 58 & 0 & 19 & 256 & 588 & 160 & 102 \\
\hline
\end{tabular}

Distribuição de Atividades (\%) Considerando Estados/Percentagem geral

\begin{tabular}{|c|c|c|c|c|c|c|c|c|c|c|c|c|c|c|}
\hline Estado & $\overline{\mathrm{BMM}}$ & $\overline{\text { BTocaM }}$ & Bmama & BPegaO & BVocaliza & BSorri & $\overline{\mathrm{BFOl}}$ & $\overline{\mathrm{O} B C H}$ & EB2V & EB2V1 & EB2V2 & EB2V3 & EB2V4 & $\mathrm{B} 2 \mathrm{~V} 5$ \\
\hline 1 & 1,78 & 0, & 0 & 0 & 0,89 & 0,00 & 1,44 & 0,00 & 0 & 2 & 0,89 & 0,11 & 0,22 & 0,11 \\
\hline 2 & 18 & & 1 & & 8 & 0 & 13,33 & 0 & & & 28 & 0 & 3 & 0,33 \\
\hline 3 & 5 & 24 & 19, & & & 0,22 & 5,11 & 2,78 & & & 0 & 65,33 & 89 & 5,22 \\
\hline 4 & & 10 & & & & 0 , & 1,56 & 4,44 & & & 3 & 9,89 & 17,78 & 5,22 \\
\hline 5 & & & & & & & 1,22 & 3,33 & & & 0,33 & 5,22 & 22 & 11,33 \\
\hline Total & 83,67 & 33,00 & 38,11 & 0,00 & 48,89 & 0,22 & 18,89 & 6,44 & 0,00 & 2,11 & 28,44 & 65,33 & 17,78 & 11,33 \\
\hline
\end{tabular}


Os contextos específicos de troca mais apropriados para as interações se transformam no curso do desenvolvimento. No presente estudo, onde foram observados bebês com idade média de 29 dias em suas casas, os contextos específicos de troca das díades foram restritos, como já era esperado. Predominaram nos episódios de interação: bebê no colo da mãe, mamando $(n=30)$, bebê no colo da mãe sem estar mamando $(n=13)$ e cuidado, como: trocar fralda, vestir, dar remédio $(n=8)$.

Foram observados 53 episódios de interação, com uma duração média de 22,4s, variando entre 6 s e 2 min e 5 s. Mesmo com a faixa de variação observada, pode-se dizer que foram, em geral, curtos os episódios em que mãe e bebê estavam engajados. Parecem ser, principalmente, as características do bebê, como parceiro, que impõem limites temporais à interação.

As durações médias dos episódios de interação variaram nos diferentes contextos de troca: cuidado (9,75s), bebê no colo sem estar mamando (21,9s) e bebê no colo mamando (26,5s). A maior duração dos episódios de interação no contexto de amamentação pode ser explicada pelo fato de que a posição em que os parceiros se encontram é facilitadora de maior engajamento, no sentido da manutenção do contato visual. A distância pequena em que os rostos dos dois ficam um do outro também parece propiciar o prolongamento do contato visual. Outro aspecto que deve ainda ser levado em conta é que a própria atividade de amamentação tende a durar mais tempo do que outras como trocar fralda, por exemplo.

As díades observadas realizaram, predominantemente, trocas face-a-face, que parecem ser características do início do desenvolvimento neste tipo de investimento parental (ocidental). Em grande parte dos episódios identificados, mães e bebês olhavam-se mutuamente e as mães, ao mesmo tempo, falavam com os bebês, acariciavam, sorriam e atribuíam significado aos comportamentos deles. Os ajustes posturais das mães feitos na tentativa de melhor acomodar os bebês e facilitar o contato visual entre eles, devem ser destacados. Os bebês, com um repertório de comportamentos mais restrito, tendiam a olhar para o rosto das mães e a movimentar os membros. Embora pouco freqüentes, foram identificadas interações nas quais não ocorreu o contato visual mãe-bebê. As interações foram iniciadas tanto pelas mães, através do olhar, fala, vocalização, quanto pelos bebês, através do choro, vocalização e olhar.

Observa-se, analisando-se as percentagens dos diferentes estados de vigília nos intervalos em que ocorreram episódios de interação, que na maioria deles, o bebê estava acordado e alerta $(66,2 \%)$. Em 7,2\% estavam inquietos e em 1,2\% estavam chorando. Apenas em $22 \%$ dos intervalos em que foram observadas instâncias de interação, o bebê estava sonolento. Mais de um estado de vigilia podia ocorrer e ser assinalado em um mesmo intervalo.

Foram observados 14 episódios de tentativa de interação, distribuídos em diferentes contextos específicos de troca, e com duração média de 16,9s. Predominaram tentativas no contexto específico em que a mãe está sentada ao lado do bebê, geralmente na cama do casal. As tentativas observadas foram todas realizadas por parte das mães e tiveram como objetivo: mudar o estado do bebê, chamar a atenção do bebê para si, ou chamar a atenção do bebê para o ambiente. A atenção das mães sobre os estados de vigilia dos bebês e a tentativa de modificar estes estados de acordo com o contexto puderam ser observados. Em alguns momentos as mães tentavam não deixar os bebês adormecerem enquanto eram amamentados, em outros, agiam no sentido de tranqüilizar os bebês, para lhes proporcionar mais conforto.

A percentagem de intervalos em que o bebê estava sonolento e em que foram identificadas tentativas de interação $(33 \%)$ é maior do que no caso de interações. Isto se explica, em parte, porque a forma mais freqüente que as tentativas de interação das mães assumiram foi a de tentar mudar o estado do bebê, como apontado acima. Estas tentativas ocorreram principalmente no contexto de amamentação, em situações em que o bebê demonstrava passar do estado alerta ao sonolento ou ao sono e as mães agiam no sentido de trazê-los novamente ao estado alerta para que continuassem mamando. Nos demais tipos de tentativas, as mães se utilizavam de pistas posturais, vocalizações, falavam e chamavam os bebês no intuito de fazer com que se engajassem com ela ou prestassem atenção a um objeto no ambiente.

Considera-se que os estados de vigilia do bebê constituem um dos elementos importantes da auto-regulação recíproca. Observou-se, a partir da análise qualitativa dos vídeos, que as mães tendem a levar em conta informação sobre o estado do bebê para guiar seu comportamento. A diminuição das atividades de interferência, utilizando-se a terminologia empregada por Brazelton e Cramer (1992), ou seja, falar com o bebê, vocalizar, tentar chamar a atenção dele durante a amamentação, como identificado nas análises, é um bom exemplo nesse sentido. Por outro lado, a análise dos estados de vigília dos bebês que predominaram durante os episódios de interação e tentativa de interação não efetivada revelou que a maior parte destes episódios ocorreu no estado 3. Isto indica que o bebê estava mais alerta e comunicava isto à mãe pelas atividades que realizava (olhar, movimentar os membros, vocalizar), e a mãe respondia também com mais atividade, o que favorece a ocorrência de trocas interativas.

Outro aspecto que deve ser ressaltado é a variedade de ajustes que as mães fazem em seus comportamentos de modo a poder melhor se relacionar com os bebês. Estes incluem, entre outros, a realização de mudanças posturais, como posicionar o rosto na direção, altura e com proximidade ao rosto do bebê, a criação de situações facilitadoras de interação, a seleção de meios de comunicação mais adequados para se dirigir ao bebê em diferentes contextos e a regulação de suas próprias atividades em função dos estados de vigilia do bebê, como já comentado.

Ainda no que se refere às mães, deve-se destacar o quanto estas se apropriam das ações comunicativas dos bebês, dão a 
elas um significado, as interpretam de acordo com suas referências, e agem, em resposta aos bebês, de acordo com esta interpretação. Isto se revela, em parte, nas falas que são classificadas nesse estudo como de 'atribuição de significado'. Cabe lembrar que, numa opção conservadora, só foram classificadas desta maneira manifestações explícitas da fala da mãe. Foram observadas 199 instâncias de atribuição de significado, a maioria delas sobre 'preferências/vontade' (52,8\%). As demais foram sobre 'estados emocionais' (16\%); 'condição/sensação física' (16\%); 'necessidades básicas/fisiológicas' (14,6\%) e 'capacidade cognitiva' $(0,6 \%)$. O fato das atribuições feitas pelas mães e reveladas em suas falas mostrarem-se predominantemente vinculadas a preferências e vontades dos bebês revela uma concepção de que estes últimos, desde muito cedo, mostram-se capazes de fazer uma série de discriminações sensoriais e ter, conseqüentemente, diversas preferências.

Embora, de modo geral, as mães tenham apresentado os mesmos comportamentos durante as interações, foram identificadas certas particularidades e diferenças individuais entre elas. Os estilos de lidar com os bebês variaram. Em relação às atividades de cuidado, por exemplo, algumas mães realizavam as tarefas com os bebês de forma rápida, eficiente e mostravam-se menos atentas aos sinais comunicativos e comportamentos dos bebês. Outras, realizavam as tarefas mais lentamente, aproveitando as atividades executadas naquele contexto como elementos para a interação, ou seja, falavam com os bebês sobre o que estavam fazendo e atribuíam a eles estar ou não gostando daquelas atividades. Na amamentação, os estilos também diferiram. Algumas mães permaneciam atentas ao bebê durante a amamentação, olhando para eles e os acariciando. Outras tendiam a realizar tarefas enquanto amamentavam, como, por exemplo, ver televisão.

Escores totais no QCBR foram calculados. Escores mais altos no QCBR indicam uma visão mais positiva e acurada das competências de bebês. $\mathrm{O}$ grupo de mães que respondeu ao questionário obteve um escore total médio de 139,94 ( $d p=14,07$ ). Trata-se de um escore médio alto, compatível com resultados obtidos em um estudo realizado com adultos por Seidl de Moura, R. Ribas, A. Ribas e Correa (submetido). O resultado obtido no presente estudo é semelhante ao obtido em uma amostra de mulheres e que foi superior ao resultado médio obtido em uma amostra de homens (Seidl de Moura \& cols., submetido). Supõese que o escore médio alto, obtido também nesta amostra de mulheres, corrobora a interpretação de que a visão mais positiva das competências dos bebês se dá em função do processo de socialização das meninas, que são orientadas para assumir papel parental, o que pode levá-las a uma maior atenção e reflexão sobre o assunto. As mães avaliaram, portanto, de forma bastante positiva e acurada as competências do bebê recém-nascido, considerando-o como um ser ativo e participante das trocas sociais. Isto também se relaciona com seu nível de escolaridade.

Buscou-se identificar correlações entre os escores totais e parciais obtidos com o QCBR e a percentagem de ocorrência das seguintes atividades da mãe: falar, sorrir, tocar o bebê, atribuição de significado, e com a variável presença de interação (expressa em termos de número de episódios identificados e/ou percentagem de ocorrência). Não foram identificadas correlações significativas entre os escores do QCBR e as variáveis de interação (freqüência e percentagem de ocorrência por intervalos) e tentativa de interação (idem). Foram identificadas correlações significativas entre os escores totais e as seguintes atividades das mães: falar $(r s=0,52 ; p<0,05)$, sorrir $(r s=0,56 ; p<0,05)$ e atribuir significado $(r s=0,45 ; p<0,05)$.

A identificação de correlações entre falar e sorrir, por parte da mãe, e o escore total no QCBR mostra uma congruência entre o status que as mães atribuem a seus bebês recém-nascidos e a forma como agem em relação a eles. Parece que quanto mais as mães consideram os bebês competentes, mais lidam com eles como interlocutores e realizam mais freqüentemente atividades comunicativas do tipo falar e sorrir.

As atividades das mães e dos bebês, identificadas nos episódios de interação, foram agrupadas de modo a compor uma nova variável que expressa um 'índice geral de atividade'. O índice de atividade da mãe foi constituído por: falar, olhar o bebê, sorrir, tocar o bebê, vocalizar e atribuir significado. $\mathrm{O}$ índice de atividade do bebê foi constituído por: olhar a mãe, mamar, vocalizar, olhar ambiente e tocar a mãe. Buscou-se identificar correlações entre os escores totais obtidos no QCBR e os índices de atividade da mãe e do bebê. Os resultados indicaram uma correlação significativa entre o escore total obtido no QCBR e o índice de atividade da mãe $(r s=0,57 ; p<0,05)$.

\section{Considerações Finais}

Considera-se que o presente trabalho apresenta uma contribuição ao estudo de interações iniciais. Um conjunto de atividades comuns a mães e bebês como parceiros em trocas sociais foi identificado e algumas das características das interações iniciais nessas díades foram analisadas, investigando-se as relações entre as concepções de mães e suas atividades e interações com os bebês.

Os episódios de interação identificados são ainda de curta duração, basicamente face-a-face, ocorrem em contextos específicos e se caracterizam principalmente pelas atividades de tocar, olhar e mamar. Deste modo, aparentemente, a linha de desenvolvimento natural do bebê já lhe dá condições para as primeiras trocas interpessoais. Os episódios de interação são entremeados por tentativas de interação e por períodos de atividade individual da mãe e do bebê. Embora estes episódios tenham sido de domínio social, foi possível ilustrar o início do processo de inclusão de objetos como mediadores das trocas das díades.

Os dados obtidos com o QCBR corroboraram resultados anteriores em relação às avaliações de mulheres desta cultura urbana ocidental específica quanto às competências de recém- 
nascidos, considerando-os como ativos e participantes das trocas sociais. Mais importante do que este resultado, no entanto, são as correlações significativas obtidas entre o escore total neste instrumento, o índice geral de atividade da mãe, e as variáveis falar, sorrir e atribuir significado. Isto revela uma relação entre algumas das representações das mães e suas ações direcionadas a seus bebês recém-nascidos.

Estes achados mostram-se congruentes com a literatura internacional, e trazem elementos importantes para a discussão acerca da natureza e de aspectos universais e específicos dos primeiros processos interacionais.

\section{Referências}

Bornstein, M. \& Tamis-LeMonda, C. S. (1990). Activities and interactions of mothers and their firstborn infants in the first six months of life: Covariation, stability, continuity, correspondence and prediction. Child Development, 61, 1206-1217.

Bornstein, M. H., Maital, S. L., Tal, J. \& Baras, R. (1995). Mother and infant activity and interaction in Israel and the United States: A comparative study. International Journal of Behavioral Development, 18, 63-82.

Brazelton, T. B. \& Cramer, B. G. (1992). Asprimeiras relaçōes. São Paulo: Martins Fontes. Bruner, J. (1983). In search of mind: essays in autobiography. New York: Harper \& Row.

Fogel, A., Toda, S. \& Kawai, M. (1988). Mother-infant face-to-face interaction in Japan and the United States: Laboratory comparison using 3-month-old infants. Developmental Psychology, 24, 398-406.

Heckhausen, J. (1987). How do mothers know? Infants' chronological age or infants' performance as determinants of adaptation in maternal instruction? Journal of Experimental Child Psychology, 43, 212-226.

Kaye, K. \& Fogel, A. (1980). The temporal structure of face-to-face communication between mothers and infants. Developmental Psychology, 16, 454-464.

Keller, H. (1998). Diferentes caminhos de socialização até a adolescência. Revista Brasileira de Crescimento e Desenvolvimento Humano, 8, 1-14.

Keller,H. (1998). Different socialization pathways to adolescence. Trabalho apresentado na 4th Africa Region International Society for the Study of Behavior Development Conference, ISSBD, Windoek, Namibia, 20-23 de Julho.

LeVine, R. A. (1989). Cultural environments in child development. Em W. Damon (Org.), Child development today and tomorrow (pp. 52-68). San Francisco: Jossey-Bass.

Osofsky, J. D. \& Connors, K. (1979). Mother-Infant Interaction: An integrative view of a complex system. Em J. D. Osofsky (Org.), Handbook of infant development. New York: John Wiley \& Sons.
Ribas, A. F. P. (1996). Interaçōes precoces mãe-bebê: A gênese de zonas de construção. Dissertação de Mestrado não-publicada, Programa de Pós-graduação em Psicologia, Universidade Federal do Rio de Janeiro. Rio de Janeiro, RJ.

Ribas, A. F. P. \& Seidl de Moura, M. L. (1995). Construção de um questionário para o estudo da concepção de adultos acerca das competências do recém-nascido. Arquivos Brasileiros de Psicologia, 47, 89-99.

Ribas, A. F. P. \& Seidl de Moura, M. L. (1998). Interação precoce mãe-bebê. Cadernos de Psicologia, 9, 50-66.

Robin, M. (1980). Interaction process analysis of mothers with their newborn infants. Early Child Development and Care, 6, 93-108.

Rochat, P. (2001). The infant's world. Cambridge, Mass., and London, England: Routledge and Keagan Press.

Rochat, P. \& Striano, T. (1999). Social-cognitive development in the first year. Em P. Rochat (Org.), Early social cognition: Understanding others in the first months of life (pp. 3-34). Mahwah, New Jersey \& London: Lawrence Erlbaum.

Rosenthal, M. K. (1983). State variations in the newborn and mother-infant interaction during breast feeding: Some sex differences. Developmental Psychology, 19, 740-745.

Seidl de Moura, M. L. \& Ribas, A. F. P (1996). Mother and infant interaction: The genesis of zones of proximal development. Abstracts, Ind Conference for Sociocultural Research, Geneva, p. 45.

Seidl de Moura, M L., Ribas, R. C.; Ribas, A. F. P. \& Correa, J. (2003). A concepção de adultos sobre competências de bebês de 0 a 2 meses de idade (submetido)

Smotherman, W. \& Robinson, S. (1996). The development of behavior before birth. Developmental Psychology, 32, 3, 425-434.

Snow, C. (1994). Beginning from baby talk: Twenty years of research on input in interaction. Em C. Gallaway \& B. J. Richards (Orgs.), Input and interaction in language acquisition (pp. 3-12). Cambridge, UK: Cambridge University Press.

Tomasello, M. (1999). Social cognition before the revolution. Em P. Rochat (Org.), Early social cognition: Understanding others in the first months of life (pp. 301-314). Mahwah, New Jersey \& London: Lawrence Erlbaum.

Trevarthen, C. \& Hubley, P. (1978). Secondary intersubjectivity: Confidence, confiding and acts of meaning in the first year. Em A. Lock (Org.), Action, gesture and symbol: The emergence of language, (pp. 183-229). London: Academic Press.

Vinter, A. (1987). A imitacãa do recém-nascido. São Paulo: Manole.

Vygotsky, L. S. (1984). A formação social da mente. Rio de Janeiro: Martins Fontes.

Sobre os autores

Adriana F. Paes Ribas é Psicóloga, Doutora em Psicologia Social pelo Programa de Pós-Graduação em Psicologia Social da Universidade do Estado do Rio de Janeiro. É Professora do Curso de Psicologia da Universidade Estácio de Sá.

Karla da Costa Seabra é Psicóloga, Doutoranda no Programa de Pós-graduação em Psicologia Social da Universidade do Estado do Rio de Janeiro. É Professora da Universidade Estácio de Sá

Luciana Fontes Pessôa é Psicóloga, graduada na Universidade do Estado do Rio de Janeiro. É Mestre em Psicologia Social e Doutoranda do Programa de Pós-Graduação de Psicologia Social, na Universidade do Estado do Rio de Janeiro.

Maria Lucia Seidl de Moura é Psicóloga, Doutora em Psicologia pela Fundação Getúlio Vargas. É Professora titular do Instituto de Psicologia, Programa de Pós-Graduação em Psicologia Social da Universidade do Estado do Rio de Janeiro.

Rodolfo de Castro Ribas Junior é Psicólogo, Professor do Instituto de Psicologia da Universidade Federal do Rio de Janeiro, Doutor em Psicologia Social Programa de Pós-graduação em Psicologia Social do Instituto de Psicologia da Universidade do Estado do Rio de Janeiro.

Susana Engelhard Nogueira é Psicóloga, Especialista em Psicologia Clínica-Institucional HUPE/UERJ, Mestranda do Programa de Pós-Graduação em Psicologia Social na Universidade do Estado do Rio de Janeiro. 